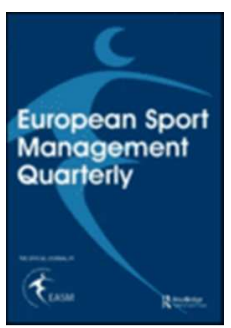

\title{
AN ANALYSIS OF COUNTRY MEDAL SHARES IN INDIVIDUAL SPORTS AT THE OLYMPICS
}

\begin{tabular}{|r|l|}
\hline Journal: & European Sport Management Quarterly \\
\hline Manuscript ID & RESM-2015-0141.R2 \\
\hline Manuscript Type: & Research Paper \\
\hline Keywords: & Olympics, medals, sports policy, tobit, marginal effects \\
\hline \multicolumn{2}{|l}{} \\
\end{tabular}

SCHOLARONE ${ }^{\text {'x }}$

Manuscripts 
Abstract

Research question: Several studies report modelling relating countries' medal shares at the Olympics to population and per capita income (host status and political system are typically included as controls). This paper uses a similar model but disaggregates to the level of the individual sport to ask questions such as whether some sports have a less steep relationship with income levels than others and whether hosting effects are more pronounced in some sports than others.

Research methods: Employing a random effects tobit model, data on medal shares are modelled across fifteen sports at six editions of the Games (1992-2012). Marginal effects, calculated for the case of cycling, illustrate how far many poor countries are from reasonable expectation of achieving medals.

Results and findings: Income is influential on outcomes in all sports, its effects most pronounced in sports with substantial requirements for specific capital equipment; the distribution of medals is less unequal in sports practised in multi-sports venues. Gains from hosting vary in magnitude, performance tending to be elevated most in sports with outcomes strongly influenced by judges.

Implications: For poorer countries, the paper identifies a small group of sports on which it would be most realistic to focus resources. For Games organisers, who must decide which sports to include, it provides information relevant to the goal of spreading success more evenly across countries. For example, proposals to exclude wrestling are shown to have been potentially harmful to medal prospects of poorer countries.

Keywords

Olympics; medals; sport policy; tobit; marginal effects 


\section{Introduction}

Shibli et al. (2014) note that, for more than sixty years, researchers have shown interest in the effects of macro-economic factors on national team performances at the Olympic Games. De Bosscher et al. (2006, Table 1, pp. 189-193) provide a tabulation of the principal features of several of the leading studies which have attempted to account for the pattern of medal counts across countries.

Studying the determinants of medal outcomes is worthwhile since, typically, welfare appears to be enhanced in a country when it achieves Olympic success. Kavetsos \& Szymanski (2010) used results from periodic happiness surveys in European countries and detected elevated self-reported wellbeing following national over-performance at the Olympics (where over-performance was defined relative to national medal tally at the preceding Games). Hallmann et al. (2013) reported that nearly two-thirds of Germans felt pride and happiness when the country won medals, with the effect greatest among female and low-income respondents. In another German study, Wicker et al. (2012) estimated a significant population willingness-topay for medals. In a BBC international poll carried out in the year leading up to the London Games, it was found that, in eighteen of 21 countries surveyed, a majority of respondents agreed that they felt proud when their country won a medal. Agreement reached $90 \%$ in Kenya, one of the few developing countries to have enjoyed significant Olympic success.

But the pride and joy experienced in populations when a medal is won is far from equally distributed across nations. The medals table is dominated by relatively rich countries. The United States regularly wins 100 medals or more at a single Games. By contrast, India and Nigeria, two of the most populous developing countries, have won fewer than fifty between them in the history of the Olympic Games. And several dozen countries which participated in 2012 had never claimed a single medal. Most of these were very poor countries.

In a heavily cited paper, Bernard \& Busse (2004) used data from 1960-1996 to confirm the importance of economic resources in determining the distribution of medals. Controlling for hosting effects and political systems, they regressed medal 
share on log population and log per capita income. Both focus variables proved highly significant and the coefficient estimates were sufficiently similar for them to conclude that, broadly, it was the size of aggregate GDP (population times per capita income) which mattered for medals totals.

Since Bernard and Busse (2004), development of the literature has been in the direction of either extending their model to include more variables (e.g. Maennig and Wellbrock, 2008, included national climate while Forrest et al., 2010, added government spending on recreation) or of widening its application to cover other major multi-sports events, including the Winter Games (Andreff, 2011).

The innovation of this paper, by contrast, is to present a slightly adapted version of the Bernard-Busse model and to use it to drill down to the level of specific sports. Our disaggregated analysis employs data from 1992-2012 to model country medal shares in each of fifteen sports (which together accounted for $84.7 \%$ of medals awarded over the period).

We expected a disaggregated analysis to serve a number of purposes.

First, it should help us understand mechanisms underlying the relationship between aggregate country performance and the covariates. These are left open by the Bernard-Busse analysis. For example, per capita income may be a positive determinant of medals won because the populations of richer countries enjoy better nutrition to enable them to practice sport to a higher level (such that more potential champions emerge from recreational sport) or because richer countries have more resources to allocate to training their Olympics teams. Similarly, hosting effects may be driven by governments spending more money on elite athletes' training programmes in the run-up to their showcase Games or may be attributable to home teams benefiting from the traditional sources of home advantage in sport, such as crowd support and familiarity with the idiosyncrasies of local venues. Significant differences in the slope coefficients between sports may illuminate which of the competing explanations for income and hosting effects are most relevant. 
Second, to the extent that inequality in the distribution of medals between richer and poorer countries is indeed a cause for concern (Groot, 2008), the results can be analysed to help us evaluate just how far poorer countries are from achieving a breakthrough in terms of medal totals: will faster growth in emerging economies produce a medals dividend in the short-term? To illuminate this issue, we will include a section illustrating marginal effects (which is a novelty in the context of this particular literature). Again, our results should be relevant to policy decisions within the International Olympic Committee (IOC) where there has been considerable controversy regarding which sports should be included in the Games. Decision-takers will be influenced by factors such as the relative value of media rights across sports but another aspect to be taken into account may be which sports mitigate and which aggravate observed inequality in the distribution of medals.

Third, for managers of elite sports in individual countries, results should aid in identifying which sports would be most realistic to target if the policy goal is for the country to win more medals or indeed to win a medal for the first time.

We leave to future research the potential of a disaggregated approach to improve forecasting models for Olympics medals. Bernard and Busse (2004) noted that their basic model became efficacious for forecasting only when a lagged dependent variable was added to the specification. Their lead results left out the lagged dependent variable because they were interested primarily in the structural relationship between medals totals and economic resources. Here we exclude countries' past performances for the same reason.

\section{Data and model specification}

The data we analyse are from six editions of the Summer Games, from 1992-2012. There is therefore only one Games common to the analysis here and that of Bernard and Busse (2004). Our choice to focus on the last six Games was driven mainly by our wanting to measure gross domestic product at purchasing power parity exchange rates and the number of country observations where this statistic was unavailable was relatively high for the period before 1992. There are other advantages to focusing on the period since 1992. First, it avoids including observations from Games subject to 
political boycotts which may have distorted medal outcomes. Second, given the importance of political variables in prior studies, it avoids potential complexity from mixing periods before and after the demise of the Soviet Union and its sphere of influence. Third, it reduces the risk of obtaining results which might be driven by conditions in now distant past times which might not be so relevant now (for example, international travel was more arduous than now, favouring host countries, and it was less common than now for athletes from relatively poor countries to receive high-level training at American universities). In any case it will be of interest how a BernardBusse type model performs for a later period with very limited overlap with the data period they studied.

Of course, even over the shorter period, there were some missing observations because of lack of gdp data though these were small in number. For example, 204 nations competed in 2012 and only eleven had to be omitted from the analysis. Except for Myanmar and Palestine, these were all very small territories, such as Cape Verde and Nauru; and none of the omitted countries won medals.

The most notable missing observation from earlier in the data set is that relating to the Unified Team in 1992. This group of athletes represented a range of countries (including Russia) which had previously been part of the Soviet Union but in which new National Olympic Committees had not yet been formed.

Even where it includes a team such as the Unified Team which won a significant number of medals, omission of a small number of countries from the estimation should not undermine the reliability of the statistical modelling. In the model specification below, year dummy variables account for factors reflecting how hard it was to win medals in each particular year. For example, in a year when fewer medals are available, it is harder to win medals. Similarly, if the Unified Team is omitted from the analysis, its presence in the Games still makes it harder for other teams (included in the analysis) to win medal share and this effect will be captured in the coefficient on the dummy variable for 1992.

Medal outcomes were modelled for fifteen sports. The number of medals distributed in each sport over the data period ranged from 107 (equestrian) to 815 
(athletics). Other sports which featured in the Games were discarded from the data if the number of medals available over the whole period was smaller than 100 (for example, badminton had only 91): it might not be meaningful to model the distribution of medals across up to 200 countries where they were competing for relatively few medals. This meant that sports which are entirely team-based (e.g. football) are not covered by our analysis since few medals are at stake. Nevertheless, $84.7 \%$ of medals awarded at our Games were in sports retained for analysis and therefore the incomplete coverage still leaves the results highly relevant when discussing drivers of the aggregate distribution of medals.

Medal shares in each Games by sport were calculated as if every country represented at the particular Games was eligible to win a medal in any given sport, even where they did not field any athletes in that sport. The implicit assumption here was that countries which do not take part in all sports will choose to be absent from those where they have no realistic chance of a medal. Medal shares were calculated from medals tables on the International Olympic Committee website (www.ioc.com).

The raw data illustrate that the degree of inter-country inequality in medal outcomes can differ sharply across sports. For each of our fifteen sports, at each Games between 1992 and 2012, we calculated the Herfindahl- Hirschman Index (HHI). This statistical indicator was devised originally to summarise the degree of market concentration in an industry: the higher the Index, the greater the degree of market concentration. Thus the maximum possible value of 1 would represent a situation where a single firm was responsible for $100 \%$ of the sales in the market. Latterly the Herfindahl- Hirschman Index has been adapted to become a popular way of measuring competitive balance in sports leagues (Owen et al., 2007). Here we use it to measure how the extent to which medal success is concentrated in relatively few countries varies across sports.

Table 1 indicates that differences in concentration between sports are often substantial and persistent over time. For example, the index for diving is always several times as high as that for athletics, i.e. there is a persistent tendency for success in the diving competitions to be concentrated in fewer countries than in athletics. Our modelling will reveal whether such differences can be related to differences between 
sports in the degree of influence of per capita income and other variables similar to those included in Bernard and Busse (2004). However, we acknowledge that sportspecific explanations may also be relevant. For example, athletics has much more heterogeneity in events than diving. A country which specialises in long-distance running would not necessarily be successful in, for example, throwing events; by contrast, diving events are relatively similar to each other and a country which gains a comparative advantage in one event is likely to be pre-eminent in all the other events as well.

Again, the rules on entry imposed by individual international sports federations may also be influential. For example, sailing is a sport requiring substantial expenditure on capital assets and medals might therefore be expected to be highly concentrated in a few very rich countries. However, in each sailing event, a country is permitted only one boat and it can therefore win only one of the medals. This constrains and forces down the value of the HHI. Relatively low values of the HHI are also recorded for other sports with entry restrictions: boxing, judo and wrestling (which each allow a country only one competitor at each weight category), shooting (two per event) and rowing (one per event).

[Table 1 near here]

Like Bernard and Busse (2004), we modelled a country's medal share at Games $t$ employing a random effects tobit model in recognition of the large mass points at zero medal share. The data are therefore treated as subject to censoring, which is intuitive because some countries come closer than others to winning a medal, for example they may win some fourth-places, yet the performances of all of them are recorded as zero.

Other categories of model which account for large numbers of zeros have been used in work on Olympic medal outcomes. For example Lui and Suen, 2008, estimated models which related a country's medal count at a given Games to variables similar to those employed by Bernard and Busse (2004); a separate model was reported for each Games in their data period. They presented results for both the 
Poisson model and the negative binomial model (with the former found to be more efficient).

However, we chose to follow Bernard and Busse (2004) by employing the random effects tobit estimator. First, this facilitates comparisons with their results. Second, it is hard to think of theoretical reasons why the tobit model would be inappropriate: a general limitation of tobit in dealing with data where there are many zeros (because negative values cannot be observed) is that it imposes the restriction that the same factors determine the probability of a unit recording a positive value and the value (if positive); but in this particular context it in fact appeared to us plausible that the same mechanisms (resources) would indeed drive both whether a country would win medals and how many it would win if it did. Third, our focus was to be on individual sports. Poisson is a count model and the size of coefficient estimates for a sport would depend in part on how many medals were available in each sport in each Games. Comparisons across sports would therefore not be straightforward. By focusing on medal shares, we would be able, from the coefficient estimates, to compare sports in terms of the magnitude of relationships between medal performance and each explanatory variable: the model results for each sport would be to the same scale if medal share rather than medal count were to be the focus.

Again, as in the Bernard-Busse specification, covariates include the natural logarithms of per capita GDP and population for which data were obtained from World Development Indicators, 2014 (published by the World Bank). Host takes the value 1 for a Games where the country was host.

Two series for per capita GDP were potentially available: it could be measured in current USD or at purchasing power parity exchange rates; the latter controls for differences between costs of living across different countries at a point in time. Using the 'current USD' basis would have had the advantage that there were relatively few missing values whereas purchasing power parity series were not reported for many countries before the 1990s. However, the effect of per capita GDP on medals is likely to be mediated through the level of resources that can be channelled into elite or recreational sport. We therefore found compelling the argument in De Bosscher et al. (2015, Section 5.3) that using 'current USD' was less appropriate since a given level 
of resources measured in USD at the current exchange rate might buy considerably more sporting goods in one country than in another. Standardisation in terms of purchasing power should therefore enable more precise and reliable estimation of the relationship between medal share and per capita income. We note though that the key results reported below retained the same patterns when we estimated models using current USD and for the longer run of Games which this enabled us to include in the analysis.

The economic resources model hypothesises an advantage for countries which have greater resources of population and income than others, so it implies that it is relative rather than absolute population and income which matter: a given population/ income level will yield decreased medals share over time if other countries experience an increase in these variables. Therefore time dummies are included in our specification to account for variations in World population and income levels (and will also account for variation in the real value of a dollar).

Finally, Bernard and Busse included political system dummies to capture elevated performance by countries in the Soviet bloc and by other planned economies (e.g.,China). Here we had to adapt their model since our data set relates exclusively to the period after the dissolution of the Soviet Union and the formation of new countries in Eastern Europe. We have three 'political' dummy variables. Ex-Soviet Union indicates that a country had, prior to 1990, been part of the Soviet Union (e.g. Russia, Ukraine, Kazakhstan). Ex-Soviet bloc includes other countries whose whole territory had been in a country within the sphere of influence of the Soviet Union as part of either the Warsaw Pact or Yugoslavia. Planned describes other planned economies which notably include China and Cuba.

The rationale for these distinctions is that all countries which had been in the Soviet Union or within its sphere of influence might have been expected to continue to over-perform even after the political upheavals to the extent that they had a legacy from the sporting infrastructure in place. But those which had been in the Soviet Union itself largely remained as relatively autocratic states (the Baltic states were the exception) whereas the others turned to the West and became relatively democratic, 
with governments more accountable to their populations. In such states, there would have been less scope for governments to allocate scarce resources to the production of medals regardless of the views of their electorates. In these states there was also a step fall in participation in recreational sport (Popaux, 2006), which would tend to decrease the supply of elite athletes.

Our model was therefore:

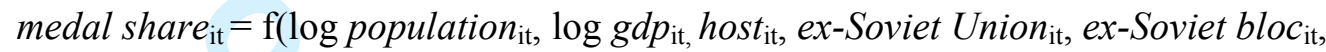
planned $\left._{\mathrm{it}}, t_{1} \ldots t_{6}\right)$

where subscripts $i$ and $t$ index countries and time respectively and $t_{1} \ldots t_{6}$ are time dummies.

Table 2 illustrates the efficacy of the model whose results are presented in the following section in terms of its accounting for the proportion of countries which record a non-zero medal share in each sport. The figures relate to the 2012 Games. In terms of the aggregate medal results across our fifteen sports, the fitted values estimate that $41.0 \%$ of countries (80) 'should' have won at least one medal and this is exactly the percentage which actually won a medal. However, as the 'accuracy index' illustrates, for individual sports other than athletics there was a tendency for more countries to win a medal relative to the number suggested by the model estimates. This may be attributed to noise being more significant in the generation of outcomes in subsets of the Olympic Games compared with the whole Olympic Games. Noise may be associated, for example, with some random distribution of extreme talent across the World. Thus the model results did not suggest that such a poor (and small) country as Zimbabwe would win a swimming medal in any Games. But it won seven across the Athens and Beijing Olympics, all obtained by one swimmer (Kirsty Coventry) with extraordinary talent and access to international-level coaching through an athletics scholarship in the United States. Neither a tobit model nor any other model based on macro covariates could have anticipated Zimbabwe's performance in swimming over this period.

[Table 2 near here] 


\section{Results}

Table 3 displays our model estimates by sport. The final two rows present results from modelling medal shares in the aggregate both for the set of sports we analyse and for all sports which featured at the editions of the Games included in our sample.

Generally, the strong significance of $\rho$, the proportional contribution of the panel-level component to the total variance, validates the employment of a random effects estimator. Treating the data as panel, rather than pooling the observations, is preferred.

As in Bernard \& Busse (2004), the coefficient estimates on log population and log gdp in the 'all sports' results are almost identical. However, their magnitude is a little lower than Bernard and Busse (2004) reported for their earlier period, consistent with the suggestion (De Bosscher et al., 2006) that the importance of macro variables, while still very high, may have lessened over time. One of the possible explanations is that sports have become more globalised and more athletes representing relatively poor countries may now have access to the superior training available in rich countries, for example by migration or by taking up athletics scholarships.

It will be noted from Table 3 that coefficient estimates for the aggregate of all sports are generally substantially lower than the corresponding estimates for individual sports. This may be worthy of comment.

In the tobit model, a coefficient estimate is a conditional marginal effect: it shows the impact on the expected value of the dependent variable (medal share) conditional on a probability of 1 that the observation is not censored (i.e. that medal share is positive).

But to find unconditional marginal effects, the coefficient estimate must be weighted by the probability that the country achieves a medal share greater than zero. Naturally, the probability that a country will win a medal in any particular sport is lower than the probability that it will win a medal in the Games as a whole. For 
consistency between the disaggregated and aggregated results in terms of the size of the unconditional marginal effects, the lower probability at the level of an individual sport therefore requires that the coefficient estimate be correspondingly higher.

The results shown in Table 3 support that the economic resources model may be applied effectively at the level of an individual sport. For each of the fifteen sports, the coefficient estimate on $\log$ per capita $g d p$ is always positive and highly significant and so is the coefficient estimate on log population. The influence of hosting a Games is more heterogeneous across sports: while evidence of hosting effects is very strong in the results for 'all sports', the variable host is statistically significant (always positive) in only six of the fifteen sports investigated individually.

But, although the results reveal that the same resource drivers of national performance apply generally to all sports, the magnitude of the coefficient estimates differs across sports. It is in the patterns across sports that our main interest lies.

[Table 3 near here]

\section{Discussion}

\section{Per capita income}

A relationship between medals and per capita income is to be expected partly because elite athletes may emerge only where there is a pool of people participating in sport; and participation in sport requires the input of leisure time and consumption expenditure by individuals (to pay for sports equipment and use of facilities). Since both leisure time and money are liable to be more plentiful in higher income countries, sports participation should be more widespread, allowing more star performers to be identified per unit population, leading, potentially, to more medals.

However, different sporting disciplines have greater or lesser requirements regarding the input of time and sports equipment/ facilities and so the relationship between medals and income should differ across sports. In our results, the highest coefficient estimates on per capita gdp, and therefore the steepest gradients in the 
relationship between medals won and a country's average living standards, are found for, equestrian (0.219), fencing (.110), diving (0.104), cycling (.100) and sailing (.091). Correspondingly the five lowest coefficient estimates among the fifteen sports are for athletics (0.014), wrestling (0.027), boxing (0.029) judo (0.033) and weightlifting (0.040).

Of course it is likely to be the case that the coefficient estimate for each of these sports is influenced by idiosyncratic factors present in the Olympic competition for the particular discipline. Some of these factors were pointed out in the discussion of HHI values above. For example, an anonymous reviewer made to us the highly relevant point that medals are 'rationed' in wrestling, boxing and judo by restricting countries to one contestant per event. And in the 2012 Games, countries were permitted to send no more ten competitors each in weightlifting. During our data period, countries could enter only two swimmers for each event (whereas before 1984 a country could contest all three medals in a given event).

Such measures limit the extent to which rich countries can dominate the medal outcomes; but it is still possible for medal shares to be skewed in favour of a small number of countries. For example, in diving in 2012, each country could enter only two athletes for an individual event and one team for each synchronised event. Nevertheless, two countries still won more than half of all the medals and indeed China won 10 out of the 24 awarded (China appears to choose to specialise in a small number of sports: 39 of its total of 88 medals in London were in diving, swimming, gymnastics or weightlifting).

It is clear that understanding the barriers against less affluent countries winning medals would be enriched by detailed sport-by-sport historic analysis. Again, the development of a tradition in running events which has been evident in success for two poor countries, Jamaica and Ethiopia, no doubt contributes to the low coefficient estimate for athletics. Nevertheless, from our more general and macro approach, consideration together of the identity of the five most elite sports and the five most democratic sports suggests a pattern: that sports are more elitist (in terms of which countries have a realistic chance of medals) the greater the extent to which they have specific (and high) capital requirements. 
It is obvious that participation in equestrian and sailing requires (heavy) investment in bloodstock and boats/ harbours respectively; and although cycling can be practiced on roads, track cycling requires the availability of both a specialist track, which has no obvious alternative use, and bicycles which are purpose-built for racing (an additional factor is that success in both cycling and sailing appears to be related to the application of scientific research which is more affordable in affluent societies). And diving pools are an expensive addition to swimming facilities, again with no obvious alternative use.

Fencing is also an expensive sport notwithstanding that it does not require specialist venues. For example, Stewart (2015) provided estimates for an Australian audience of how much it would cost for an individual to take up and practice the sport. She estimated that initial costs, mainly for expensive equipment such as a protective face mask and a weapon, would be AUD1,315, with ongoing annual costs of AUD4,000. Further, competitive fencing requires very expensive jackets and swords because each has to be electrified to allow points to be recorded in an automated way when there is contact between the sword and the opponent's jacket. Fencing is therefore firmly within the set of sports where participation requires investment in expensive specific capital equipment.

It is unsurprising, then, that the five sports we identify as most elitist offer relatively little hope of medals outside the richest countries. By contrast, the five most 'democratic' sports have little need of investment in specific capital by individuals- or by communities since wrestling, boxing, judo, weightlifting and many athletics events can be practiced in multi-purpose sports halls. Within athletics, running may be practiced even without sports halls, in parks and recreational areas and even on public roads.

It may be presumed that training Olympics athletes is expensive in any sport; but the binding obstacles to Olympics success by poor countries may consist of impediments to mass participation in sport and these impediments may be liable to be overwhelming where investment in specific capital is a prerequisite. Drawing on data 
from UNESCO, Andreff (2001) documented how little exposure to sport there was for the populations of less developed economies but noted that, where there was any participation in individual sports, it was often confined to the disciplines of athletics, judo and wrestling, none of which are what he calls 'sophisticated' sports with particular technical requirements. It is striking that these three sports are all included in our set of the five most 'democratic' sports in terms of Olympics medals.

The IOC determined in 2014 that a cap should be placed on the size of future Games as defined by the total number of medals to be awarded. New sports could in future be admitted but only if current numbers of medals in the present set of sports were correspondingly reduced. There is a case for retaining the most 'democratic' sports. From our results, wrestling offers more hope than most sports of a medal for countries with lower living standards (wrestling gave India one of its rare medals in 2012); yet, in 2014, the IOC proposed wrestling for complete exclusion from future Games (though it was subsequently reinstated). The IOC could use our results to inform its decisions on which sports to include in, or exclude from, future Games. Further, results are relevant to its decisions on how Olympic solidarity payments, designed to help poorer countries develop new facilities and programmes, should be spread across sports.

\section{Hosting effects}

In the two equations for medals aggregated across sports (Table 3 ), the tendency for host nations to 'over-perform' is very clearly evident. Since all hosts in the period were populous and/ or affluent countries which would have had a very high probability of securing a non-zero medal share, the coefficient size (about 0.2 ) can be interpreted directly as a marginal effect: a host gains on average an increase of 0.2 percentage points in its medal share, which at the current size of Games amounts to about twenty extra medals.

One reason that host nations tend to win extra medals may be that they tend purposely to allocate additional resources to athlete preparation because it is 'their' Games. But traditional home advantage, arising from factors such as crowd support (perhaps mediated through referees' and judges' decisions) and familiarity with local 
conditions would also be expected to be a source of elevated performance and here the degree of advantage should differ between sports. Hence it is of interest to consider coefficient estimates for individual sports.

While the host effect is strongly supported for the aggregate of sports, its presence proves harder to detect for individual disciplines. In fact in only six cases is the coefficient estimate statistically significant: diving (0.100), gymnastics (0.071), boxing (0.058), sailing (0.058), rowing (0.052) and judo (0.032).

Previous literature has focused on the potential of biased officiating to account for differences between events in the degree of host advantage observed in Olympic competitions. Balmer et al. (2001) predicted that "the effects of biased officiating are potentially most dramatic in sports in which the officials actually score the points through judging the performance of athletes with some combination of objective and subjective criteria"; they gave the examples of gymnastics, diving, figure skating and freestyle skiing. Their predictions were borne out in their study of host medal shares (compared with shares when the country was not hosting) at events in the whole history of the Winter Olympics to 1988. The group of events which were subjectively judged exhibited significantly greater home advantage than other events.

For the Summer Olympics, Balmer et al. (2003) studied the relative performance of host nations before and after World War II in five sports: athletics, gymnastics, weightlifting, boxing and (the aggregate of) team sports. Sports regarded as 'objectively judged', athletics and weightlifting, displayed no home advantage in terms of additional medals share. However, home advantage was present in team sports (where officials are influential but do not directly score the competition) and also in the 'largely subjectively judged sports' of boxing and gymnastics. In the postWar period, home advantage was highest in these subjectively judged sports. The results from studying home advantage in non-Olympic settings have generally been consistent with this pattern. For example, Balmer et al. (2005) found that home wins in European boxing were more likely where a bout was decided on points (awarded by the judges) rather than by a knock-out. 
Our empirical strategy differs from that of the Balmer et al. (2003) Olympics study but confirms their conclusion that there is strong host advantage in boxing and gymnastics (and none detectable in athletics and weightlifting). Further, we were able to look at additional sports and identified diving and judo as other examples of sports with host 'over-performance'. Diving is similar to gymnastics (and in the Winter Games to figure skating) in that it is scored by judges and their criteria are partly aesthetic. Judo is a rather different case but it has been argued to be a discipline where referees have to take complex and often controversial decisions which have the potential to have a strong influence on the result (Dosseville et al., 2011).

In the other two sports where we found significant host effects, rowing and sailing, the role of officials is not so influential. However what these two have in common is obviously that events take place outdoors and in water. They are therefore subject to environmental influences. This should give greater scope for hosts to be at an advantage (for example, their sailors will be familiar with local wind and wave conditions) compared with in sports such as swimming and (most of) athletics which are played indoors in facilities conforming to common specifications across international competitions.

Olympic hosts often gain more medals than they have obtained at other Games. In estimating the relationship between medal share and host status at the aggregate level, there is a danger that results will conflate the effects of greater investment in athlete preparation for a home Games and the effects of playing at home. Disaggregation by sport enables us to infer from the pattern of results across sports that traditional sources of home advantage play an important part in winning extra medals for the host nation. Consistent with previous literature, 'judged sports' show strong host advantage. This is consistent with a hypothesis that crowd support can influence judges which can influence outcomes. We did not find significant host advantage in athletics or swimming where crowds are very large but officials seldom influence outcomes. This suggests a limited effect of crowd support mediated through athlete motivation and performance. Familiarity with local conditions is another factor favouring hosts but it appears from our results to be relevant in the Olympics only in sports played outdoors. 


\section{Political variables}

Political variables are not our focus as they are included as controls to facilitate more precise estimation of the relationships between medal share on the one hand and per capita income and host status on the other. However, results provide some points of interest.

Bernard and Busse (2004), employing Olympics data from mainly the old Soviet era, reported that "Soviet countries have medal shares more than 6.1 percentage points higher than other countries" [controlling for population, per capita GDP and host status]. Our data relate to the post-Soviet era. We divide the group of countries which were once communist according to whether they used to be part of the Soviet Union or just under its influence. In the models for the aggregate of sports (Table 2), dummy variables representing each group are statistically significant albeit the magnitude of the effect is much lower than that reported for the broad group of 'Soviet bloc' countries reported in Bernard and Busse (2004). This suggests that, while the formerly communist states do not perform to the same standards as in the past, there has been a legacy effect still evident in Olympics results since 1992.

As we hypothesised above, the estimated legacy effect is greater for countries which were part of the old Soviet Union rather than just in its sphere of influence. The latter group has tended towards democracy which does not facilitate excessive allocation of resources to elite sport. On the other hand, the difference between the two groups of countries does not extend to every individual sport. In particular both groups appear to have maintained exceptional levels of performance in gymnastics and in weightlifting in particular.

\section{Marginal effects}

The discussion has been carried out through references to the relative sizes of coefficient estimates across sports. But how are the results to be interpreted in terms of the absolute impact on expected medal shares as values of the covariates change? 
To obtain the unconditional marginal effect from the tobit results, the coefficient estimate has to be multiplied by the probability estimate (Greene, 2008, p.870). For the 'biggest' Olympics countries, the probability that the country will secure a medal is very high and for these countries it is safe to approximate the marginal effect with the coefficient estimate. But this is not so for smaller and poorer countries.

That Bernard and Busse (2004) and successor papers refer to coefficient estimates as if they are marginal effects may reveal an implicit bias in favour of looking at the process of medal generation only from the perspective of rich, populous countries. Here we focus on poorer countries. But, in any case, because we model medals by sport rather than in the aggregate, probability of positive medal share at any one Games is further from 1 for each country and therefore the distinction between coefficient estimates and marginal effects becomes more widely relevant.

In Table 4, we illustrate marginal effects for one sport and five countries to show how insensitive some countries' medal performances are likely to be if, for example, they were to achieve faster growth than in the rest of the World. The chosen sport to illustrate the point is cycling, which is one of our group of elite sports. Our five countries are USA, China and Russia (the giants of the contemporary Olympics Movement), Brazil (of interest because it was selected as the host of the 2016 Games) and Honduras. Choice of the last was arbitrary from a list of countries which were relatively small (but not micro states) and relatively poor (but not among the very poorest). All marginal effects were calculated with values of covariates set to observed values at the end of our data period (2012).

[Table 4 near here]

For Honduras, the probability that the value of the latent variable exceeds zero is close to 0 whereas for the USA it is close to 1 . So, while the marginal effect for the USA is close to the coefficient estimate, this is not true for Honduras. Even for a 
populous middle-income country like Brazil, the marginal effect is sufficiently low that even significant growth in its level of income compared to other countries would be unlikely to make a material difference to its prospects. In 2012, the model forecast for its expected number of medals in cycling was approximately 0.8. And it in fact achieved none; the best ranking position of any of its six entrants in track and road cycling was $18^{\text {th }}$. As regards Honduras, it has never won a medal in any sport and in 2012, apart from the men's football team, it sent only nine athletes in eight sports. It is perhaps interesting that the eight sports were exactly the same as the eight sports in our analysis with the lowest coefficient estimates on log per capita gdp.

The results from consideration of marginal effects illustrate how stacked the odds are against poorer countries in terms of their winning more Olympics medals in the near- and medium-term. Further proactive policy by the Olympics Movement is likely to be needed if inequality is to be addressed. Potential policies suggested by the findings in this paper include (i) a redistribution of the medals awarded towards the sports identified as yielding the least pronounced relationship between success and income level, (ii) introduction of new sports (karate might be an example) which are practiced in multi-sports settings and (iii) the redirection of revenue from the Olympics towards supporting and maintaining multi-sports infrastructure in poorer countries.

\section{Disclosure statement}

None of the authors has a conflict of interest in respect of this article. 


\section{References}

Andreff, W. (2001). The correlation between economic underdevelopment and sport. European Sport Management Quarterly, 1, 251-279.

Andreff, M. \& Andreff, W. (2011). Economic predictions of medal wins at the 2014 Winter Olympics. Working Paper 11-16, College of the Holy Cross, Worcester, Mass., 2011.

Balmer, N.J., Nevill, A.M. \& Lane, A.M. (2005). Do judges enhance home advantage in European championship boxing? Journal of Sports Sciences, 23, 409-416.

Balmer, N.J., Nevill, A.M \& Williams, A.M. (2001). Home advantage in the Winter Olympics (1908-1988). Journal of Sports Science, 19, 129-139.

Balmer, N.J., Nevill, A.M. \& Williams, A.M. (2003). Modelling home advantage in the Summer Olympic Games. Journal of Sports Sciences, 21, 469-478.

Bernard, A. B., \& Busse, M. R. (2004). Who wins the Olympic Games: Economic resources and medal totals. Review of Economics and Statistics, 86, 413-417.

De Bosscher, V., De Knop, P., van Bottenburg, M. \& Shibli, S. (2006). A conceptual framework for analysing sports policy factors leading to international sporting success. European Sport Management Quarterly, 6, 185-215.

De Bosscher, V., Sibli, C., Westerbeek, H., \& van Bottenburg, M. (2015). Successful Elite sport policies. An International Comparison of the Sports Policy Factors

Leading to International Success (SPLISS 2.0) in 15 Nations. Maidenhead: Meyer and Meyer Sport (UK) Ltd.

Dosseville, F., Laborde, S. \& Raab, M. (2011). Contextual and personal motor experience effects in judo referees' decisions. The Sport Psychologist 25, 67-81.

Forrest, D., Sanz, I. \& Tena, J. D. (2010). Forecasting national team medal totals at the Summer Olympic Games. International Journal of Forecasting, 26, 576-588.

Greene, W. H. (2008). Econometric analysis, $6^{\text {th }}$ Edition. Upper Saddle River, NJ: Pearson/ Prentice Hall.

Groot, L. (2008). The contest for Olympic success as a public good. Working Paper 08-34, Utrecht School of Economics, Utrecht, Netherlands.

Hallmann, K., Breuer, C. \& Kühnreich, B. (2013). Happiness, pride and elite sporting success: What population segments gain most from national athletic achievements? Sport Management Review, 16, 226-235.

Kavetsos, G. \& Szymanski, S. (2010). National wellbeing and international sports events. Journal of Economic Psychology, 31, 158-171. 
Lui, H-K \& Suen, W. (2008). Men, money and medals. Pacific Economic Review. 13, $1-16$.

Maennig, W. \& Wellbrock, C. (2008). Sozioökonomische schätzungen Olympischer medaillengewinne. Analyse-, prognose- und benchmarkmöglichkeiten [Socioeconomic Estimation of Winning Olympics Medals: Analysis, Prognosis and Benchmark Possibilities]. Sportwissenschaft, 38, 131-148.

Owen, P.D., Ryan, M. \& Weatherston, C.R. (2007). Measuring competitive balance in professional team sports using the Herfindahl-Hirschman Index. Review of Industrial Organization, 31, 289-302.

Poupaux, S. (2006). Soviet and post-Soviet sport. In: W. Andreff \& S. Szymanski (Eds.), Handbook on the Economics of Sport (pp. 316- 324). Cheltenham: Edward Elgar.

Shili, S., De Boscher, V. \& Van Bottenburg, M. (2014). Measuring and forecasting elite sporting success. In I. Henry \& L-M Ko (Eds.), Routledge Handbook of Sport Policy (pp. 212-224). Abingdon, Oxon: Routledge.

Stewart, R.C. (2015). The cost of becoming interested in fencing as an adult. The Billfold, April 22, 2015.

Wicker, P., Hallmann, K., Breuer, C. \& Feiler, S. (2012). The value of Olympic success and the intangible effects of sports events- A contingent valuation approach in Germany. European Sport Management Quarterly, 12, 337-355. 
Table 1. Herfindahl- Hirschman Index for medal shares at Games between 1992 and 2012

\begin{tabular}{lcccccc}
\hline & 1992 & 1996 & 2000 & 2004 & 2008 & 2012 \\
\hline athletics & 0.10 & 0.06 & 0.04 & 0.07 & 0.07 & 0.08 \\
boxing & 0.07 & 0.08 & 0.08 & 0.08 & 0.08 & 0.07 \\
canoe/kayak & 0.10 & 0.09 & 0.09 & 0.08 & 0.08 & 0.12 \\
cycling & 0.11 & 0.11 & 0.11 & 0.09 & 0.13 & 0.08 \\
diving & 0.31 & 0.26 & 0.24 & 0.24 & 0.28 & 0.24 \\
equestrian & 0.22 & 0.17 & 0.15 & 0.18 & 0.17 & 0.19 \\
fencing & 0.15 & 0.18 & 0.13 & 0.14 & 0.13 & 0.13 \\
gymnastics & 0.22 & 0.13 & 0.20 & 0.12 & 0.16 & 0.12 \\
judo & 0.09 & 0.09 & 0.07 & 0.08 & 0.06 & 0.07 \\
rowing & 0.12 & 0.09 & 0.08 & 0.06 & 0.07 & 0.10 \\
sailing & 0.16 & 0.05 & 0.09 & 0.07 & 0.08 & 0.09 \\
shooting & 0.10 & 0.08 & 0.07 & 0.09 & 0.09 & 0.07 \\
swimming & 0.14 & 0.13 & 0.17 & 0.13 & 0.15 & 0.14 \\
weightlifting & 0.16 & 0.10 & 0.07 & 0.10 & 0.10 & 0.08 \\
wrestling & 0.12 & 0.07 & 0.09 & 0.08 & 0.06 & 0.07 \\
all sports modelled & 0.07 & 0.05 & 0.04 & 0.05 & 0.05 & 0.04 \\
all sports in Games & 0.06 & 0.04 & 0.04 & 0.04 & 0.05 & 0.04 \\
\hline
\end{tabular}


Table 2. Estimated and observed number of countries winning at least one medal at the 2012 Games

\begin{tabular}{lrrr}
\hline & & & \multicolumn{1}{c}{$\begin{array}{l}\text { accuracy } \\
\text { index }\end{array}$} \\
\hline athletics & Estimated non-zeros & Observed non-zeros & 92.9 \\
boxing & $22.6 \%$ & $21.0 \%$ & 286.1 \\
canoe / kayak & $3.6 \%$ & $10.3 \%$ & 213.8 \\
cycling & $3.6 \%$ & $7.7 \%$ & 183.9 \\
diving & $5.6 \%$ & $10.3 \%$ & 273.3 \\
equestrian & $1.5 \%$ & $4.1 \%$ & 195.2 \\
fencing & $2.1 \%$ & $4.1 \%$ & 319.0 \\
gymnastics & $2.1 \%$ & $6.7 \%$ & 213.9 \\
judo & $3.6 \%$ & $7.7 \%$ & 231.4 \\
rowing & $5.1 \%$ & $11.8 \%$ & 296.8 \\
sailing & $3.1 \%$ & $9.2 \%$ & 248.4 \\
shooting & $3.1 \%$ & $7.7 \%$ & 287.8 \\
swimming & $4.1 \%$ & $11.8 \%$ & 269.4 \\
weightlifting & $3.6 \%$ & $9.7 \%$ & 255.6 \\
wrestling & $3.6 \%$ & $9.2 \%$ & 181.7 \\
all sports modelled & $8.2 \%$ & $14.9 \%$ & 100.0 \\
all sports in Games & $41.0 \%$ & $41.0 \%$ & 88.5 \\
\hline$*$ The accuracy index is calculated as (observed percentage of non-zeros/estimated percentage of non- \\
zeros)*100. A value of 100 indicates exact correspondence between the proportion of countries \\
predicted to win a medal and the proportion of countries which actually win a medal. Values above \\
(below) 100 indicate that the model under- (over) estimates the proportion of countries which win a \\
medal. & & &
\end{tabular}

URL: http://mc.manuscriptcentral.com/resm 
Table 3. Results from a random effects tobit model for medal share

\begin{tabular}{|c|c|c|c|c|c|c|c|}
\hline & $\begin{array}{l}\log \\
\text { population }\end{array}$ & $\begin{array}{l}\text { log per } \\
\text { capita gdp }\end{array}$ & host & planned & ex-USSR & ex-Soviet Bloc & $\rho$ \\
\hline athletics (815) & $0.012 * * *$ & $0.014 * * *$ & 0.008 & 0.008 & $0.020 * *$ & 0.010 & $0.823 * * *$ \\
\hline boxing (283) & $0.026 * * *$ & $0.029 * * *$ & $0.058 * * *$ & 0.066 & $0.104^{* * *}$ & $0.042 * *$ & $0.597 * * *$ \\
\hline canoe/kayak (288) & $0.030 * * *$ & $0.058 * * *$ & 0.038 & 0.052 & $0.091 * * *$ & $0.119 * * *$ & $0.642 * * *$ \\
\hline cycling $(259)$ & $0.044 * * *$ & $0.100 * * *$ & 0.005 & $0.055 * *$ & $0.127 * * *$ & 0.047 & $0.486 * * *$ \\
\hline diving (120) & $0.112 * * *$ & $0.104 * * *$ & $0.100 *$ & 0.265 & 0.193 & -0.616 & $0.702 * * *$ \\
\hline equestrian (222) & $0.087 * * *$ & $0.219 * * *$ & 0.113 & -9.332 & 9.937 & $-8.895 * * *$ & $0.703 * * *$ \\
\hline fencing (174) & $0.082 * * *$ & $0.11 * * *$ & -0.088 & $0.183 * *$ & $0.147 * *$ & $0.189 * * *$ & $0.684 * * *$ \\
\hline gymnastics (594) & $0.067 * * *$ & $0.076^{* * *}$ & $0.071 * *$ & $-0.089 *$ & $0.203 * * *$ & $0.179 * * *$ & $0.472 * * *$ \\
\hline judo (336) & $0.025 * * *$ & $0.033 * * *$ & $0.032 * *$ & $0.070 * *$ & $0.078 * * *$ & $0.044 * *$ & $0.700 * * *$ \\
\hline rowing (252) & $0.032 * * *$ & $0.062 * * *$ & $0.052 * * *$ & 0.016 & $0.092 * * *$ & $0.105 * * *$ & $0.719 * * *$ \\
\hline sailing (189) & $0.037 * * *$ & $0.091 * * *$ & $0.058 * *$ & 0.038 & $0.058^{*}$ & 0.037 & $0.576^{* * *}$ \\
\hline shooting (274) & $0.027 * * *$ & $0.044 * * *$ & 0.023 & $0.086 * * *$ & $0.095 * * *$ & $0.102 * * *$ & $0.499 * * *$ \\
\hline swimming (589) & $0.029 * * *$ & $0.046^{* * *}$ & 0.015 & 0.041 & 0.032 & $0.057 * *$ & $0.725 * * *$ \\
\hline weightlifting (233) & $0.043 * * *$ & $0.040 * * *$ & -0.008 & $0.094 * * *$ & $0.152 * * *$ & $0.106 * * *$ & $0.587 * * *$ \\
\hline wrestling (740) & $0.026 * * *$ & $0.027 * * *$ & 0.020 & 0.035 & $0.119 * * *$ & $0.050 * * *$ & $0.722 * * *$ \\
\hline all sports modelled (4576) & $0.008 * * *$ & $0.009 * * *$ & $0.017 * * *$ & 0.012 & $0.019 * * *$ & $0.009 * *$ & $0.854 * * *$ \\
\hline all sports in Games (5401) & $0.008 * * *$ & $0.008 * * *$ & $0.020 * * *$ & $0.014 *$ & $0.016 * * *$ & $0.009 * *$ & $0.861 * * *$ \\
\hline
\end{tabular}

Notes: Numbers after each sport's name indicate number of medals awarded across the six Games.

All equations also included time dummies and an intercept term. ***, **, *, indicate statistical significance at the $1 \%, 5 \%$ and $10 \%$ levels respectively. 
Table 4. Estimated marginal effects for five countries in cycling

\begin{tabular}{|l|l|l|l|l|l|}
\hline & USA & China & Russia & Brazil & Honduras \\
\hline $\begin{array}{l}\text { marginal effect (log } \\
\text { population) }\end{array}$ & 0.0435 & 0.0419 & 0.0435 & 0.0070 & 0.0000 \\
\hline $\begin{array}{l}\text { marginal effect (log } \\
\text { of per capita gdp) }\end{array}$ & 0.0997 & 0.0962 & 0.0998 & 0.0162 & 0.0000 \\
\hline marginal effect host & 0.0047 & 0.0045 & 0.0047 & 0.0008 & 0.0000 \\
\hline $\begin{array}{l}\text { expected medal share } \\
\text { in 2012 }\end{array}$ & 0.0326 & 0.0278 & 0.0328 & 0.0186 & 0.0000 \\
\hline population in 2012 & $310 \mathrm{~m}$ & $1,340 \mathrm{~m}$ & $143 \mathrm{~m}$ & $200 \mathrm{~m}$ & $8 \mathrm{~m}$ \\
\hline $\begin{array}{l}\text { purchasing power } \\
\text { parity per capita } \\
\text { (USD) in 2012 }\end{array}$ & 49,153 & 9,754 & 21,629 & 14,315 & 4,267 \\
\hline
\end{tabular}


Response to reviewers' comments on "An analysis of Country Medal Shares in Individual Sports at the Olympics" (R1)

Reviewer 1

Overall I am impressed with the manner in which the authors have responded positively to the two sets of reviewers' comments. I am satisfied that the substantive comments I made have been addressed and that in my view the paper is now publishable. There is a list of minor points below that might help to improve the paper further and I would suggest some final proof reading and tidying up. The net effect of the minor points should help to clarify what it all might mean; what the causes of variations in scores might be; and how the nature of sports, their rules and qualifying quotas might impact on things.

We thank you for your generous comments and acknowledge that attending to the points below has further improved the paper.

Minor points

Page 1 line 8- put in page reference for Table 1 in De Bosscher 2006

We have added the page numbers of the table.

Page 2 line 22 change to "The innovation of this paper, by contrast, is to present a slightly adapted version of the Bernard-Busse model and to use it to drill down to the level of specific sports."

We have changed the wording exactly as recommended.

Page 3 line10 - 'short term'

We have changed 'near-term' to 'short-term'.

Page 4 line 10 - say what you mean here, do you mean drugs?

We were not thinking only of the doping environment. Many things have changed in the World that may be relevant here. We have provided two examples to illustrate this: "(for example, international travel was more arduous than now, favouring host countries, and it was less common than now for athletes from relatively poor countries to receive high-level training at American universities)."

Page 4 line 17 - the official records suggest that all 204 NOCs took part, not 201 http://www.bbc.co.uk/sport/olympics/2012/countries?region=\&medalists=\&filter=Filter hopefully this is a typo on your part and does not affect the model!

Thank-you for pointing out the error. We miscounted and also miscounted the number of missing cases. These figures have been corrected and we also provide more detail on which countries were missing cases. The miscounting did not affect the estimation process. 
Page 4 line 22 - What impact does missing data have and how do you deal with it?

We have added a new paragraph (bottom of p.4) which explains why we think that the missing cases will not undermine the reliability of the coefficient estimates

Page 5 line 23 Table 1. This is a really interesting piece of analysis that you could do more with. First diving is shown consistently to have the highest $\mathrm{HHI}$. However sports with the lowest $\mathrm{HHI}$ vary by edition (boxing 1992; sailing 1996, athletics 2000; rowing 2004; judo 2006; and boxing, judo, shooting and wrestling 2012). With the exception of athletics there are restrictive quotas in all of these sports. Nations can enter only one fighter per weight category in boxing, judo and wrestling. Nations can qualify only one boat per event in sailing and rowing; and there is a maximum of two shooters permitted in each event. By contrast, in athletics apart from the four relay events, nations can contest all three medals in each event assuming they can produce sufficient athletes. These sports can be clustered by HHI score as follows using 2012 data: Low HHI 0.00.9: athletics, boxing, cycling, judo, sailing, shooting, weightlifting and wrestling; Medium $\mathrm{HHI}$ 0.10-0.19 canoe / kayak, equestrian, fencing, gymnastics, rowing and swimming High $\mathrm{HHI} 0.20+$ diving These clusters seem to legislate against an obvious explanation, howeverAA.

Page 5 line 28 diving $v$ athletics. Athletics is 47 different events that involve sprinting, hurdling, middle distance. long distance, walking, throwing, jumping, multievents and team relays. Different nations have different sources of competitive advantage - USA power events, Kenya middle and long distance running. By contrast diving has 10 events which are essentially the same apart from the height of the board and whether it is one diver or two (synchronised). Hence diving events are much more homogenous than athletics and it is possible to develop competitive advantage in all of them as China has done. Add to this mix the unique nature of the facility to develop diving and there may be sport-specific explanations for the HHI scores in these (extreme) contrasting sports.

On p. 6, we have added sixteen lines of new text acknowledging the potential importance of sport-specific explanations of HHI values, freely drawing on the illustrations you suggest. We agree that much more could be written on the HHI data and, given variation of rules over time as well as across sports, there is the potential to test the hypothesis that entry restrictions lower HHI. However, we think we have now extended the discussion of HHI to as long as it could go without distracting from the main theme and results of the present paper.

Page 8 line 50 - the Kirsty Coventry example is a good one as it helps to explain how sport is a globalised product not contained by national boundaries. Kirsty Coventry represented Zimbabwe but she was the 'product' of the North American universities' system whereby in return for representing her university she received a scholarship and access to facilities and coaching that were not available in Zimbabwe. In other words, the product of a different nation's system.

We have added a few words referencing Kirsty Coventry's training in the USA.

Page 8 line 59 - Table 2 -this is a useful addition to the paper, it could however be improved by including an index of its accuracy e.g. for athletics the index is $(21.0 \% / 2.6 \%)^{*} 100=93$ whereas for boxing the index is 286 , but for all sports 
modelled it is an impressive and perfect 100 .

We have added a column to Table 2, as suggested.

Page 11 line 30 - this is an interesting reference (albeit perhaps unintentional) to the tension between specialisation and diversification. Some nations e.g. China win large numbers of medals in relatively few sports; whereas others, e.g. France win small numbers of medals in a wide array of sports. Government policy and funding decisions, along with national culture and past track record, are crucial here to determining 'strategy'.

On p. 12, we have added a few (bracketed) words illustrating the concentration of Chinese medals in just four sports.

Page 17 line 30 change 'not desperate' to something a bit more academic We have changed 'desperate' to 'but not among the very poorest'

Something to think about, what if we did $\mathrm{HHI}$ scores for top 8 places rather than top $3 ?$

Something to think about indeed. Thank-you for pointing out the scope for further HHI analysis. We think it would merit a new project once the Rio results have extended the data base.

Reviewer 2

Comments to the Author This draft is much improved on the original. I have 2 minor comments for the authors to address, hopefully these can be dealt with by small supporting statements:

- There needs to be comment about selection of sports e.g. soccer is excluded, why are some sports included and some excluded?

Our criterion was to exclude sports with fewer than 100 medals over the period, e.g badminton had only 91. We have added appropriate text on p.5.

- In the modern era, national sports organisations 'produce' Olympic medals not just by expenditure on sports facilities (capital) and direct financial support to athletes but also by access to specialist coaching (labour). In the case of athletics for example, this specialist coaching may reside in developed countries such as USA. As the importance of specialist coaching seems to have grown over the last 25 years what does this imply for the authors' model? A brief comment both acknowledging this development and noting what it means for the authors' model and results is appropriate I think.

We have introduced this idea with new text in the third paragraph of the Results section of the paper. We work it in at the point where we remark that in an 'all sports' equation, coefficient estimates on income decline over time-you raise one possible contributing factor. 